\title{
Social Support And Job Satisfaction Among Academicians: A Comparison Between Public And Private University In Malaysia
}

\author{
Nor A'tikah Mat Ali, Siti Khadijah Zainal Badri, Nurul Farhana Mohd Noordin, Intan \\ Marfarrina Omar
}

\begin{abstract}
The role of social support at workplace become one of the most important variables that can give impact on employee's attitude. Closely related to employee's performance, many studies have confirmed the role of social support in enhancing employee's job satisfaction. The aims of this research is two-folds. First, to investigate the differences and second to compare the effect of social support on job satisfaction among academicians in Malaysia. Overall, a total of 420 samples were obtained, wherein 210 participants withdrawn from each setting. Data was collected using self-administrated questionnaire, and analyzed using SPSS version 22. The finding suggested that social support levels (i.e. supervisor support and co-worker support) are higher among academicians in private university. Level of job satisfaction, otherwise is higher among public university. Overall, the mean values indicated high level of social support and job satisfaction among academicians in both university. Analysis of t-Test revealed that there is no significant differences in terms of social support, however the significant being observed in terms of job satisfaction between academicians in Malaysia public and private university. This study also ascertained the positive impact of social support on job satisfaction to both samples. Implication of this study includes empirical contribution and deliberation on social support and job satisfaction. Suggestion from this study includes improving social support to enhance overall academicians' job satisfaction.
\end{abstract}

Index Terms: Social Support, Supervisor Support, Co-worker Support, Job Satisfaction.

\section{INTRODUCTION}

Industry revolution 4.0 (IR 4.0) gives a huge impact towards transforming Malaysia economy and development, including the higher education system. In the higher education, academicians are the backbone to education system, wherein this population has a great responsibility to pass on knowledge from generation to generation. At present, academicians whether from public or private, have been under a greater pressure to serve and educate the Generaration Z namely Gen-Z (born 1995 to1999) and

Revised Manuscript Received on April 19, 2019.

Nor A'tikah Mat Ali, School of Applied Psychology, Social Work and Policy, UUM College of Arts and Sciences, Universiti Utara Malaysia, Sintok, Kedah, Malaysia.

Siti Khadijah Zainal Badri, Department of Organisational and Applied Psychology, Faculty of Art and Social Sciences, University of Nottingham, Semenyih, Selangor, Malaysia.

Nurul Farhana Mohd Noordin, School of Human Resource Development \& Psychology, Faculty of Social Science and Humanities, Universiti Teknologi Malaysia, Skudai, Johor, Malaysia.

Intan Marfarrina Omar, Department of Educational Management, Planning and Policy, Faculty of Education, University of Malaya, Kuala Lumpur, Malaysia.
Generation Y called as 'millennials' (born 1983 to 1994) who is dealing with the development of technology in era of IR4.0 [1]. Dealing with many challenges, academicians today are in heightened needs to perform well. Self-directed learning has been greatly emphasized, high preparation for dynamic curriculum, and the needs to keep up with technology use and modern learning tools has overstretched this population[2]. Correspondingly, academicians today are required to be more creative and multi skilled to ensure university good sustainability in moving towards IR 4.0 era. Concurrently, high workload has been a constant crisis where juggling multiple roles are perplexing (ex. teaching, supervise student, doing a research and even administration) [3, 4].

A recent NEU Workload Survey by National Education Union in 2018 had revealed long working hours remained an important crisis, whereby academicians were still dealing with accountability work although some progress had been made. Universities commonly segregated into two main categories, namely public and private. These two are which fundamentally different. Private university is also known as an academic centre, institute, college or learning centre that is dedicated to making learning and business a key aspect for success[5]. University with this status is established with the focus on business orientation. Their framework focuses on business sustainability, with common strategy includes highlighting organisational achievement, excellent staff performance and thriving and innovative culture. Otherwise, public universities focus more on community. This type of institution is giving more emphasis on innovative behaviour and development as well as creativity cultivation. In addition, public university often put more focus on research activities and teaching-based on research and development (R\&D).

Although public and private universities are disparate in terms of its mission and vision, however, academicians in both universities faced similar workload crisis. Evidence from previous research demonstrated negative impact of excessive workload on academician productivity and effectiveness [3]. As such, the management needs to be more sensitive and offer possible solution to help academicians cope with this situation since high workload is detrimental to well-being and overall performance [6]. One 
of the positive attitude that can be promoted is social support. Social support could be received from the coworker, organisation or supervisor. It is a series of experience of being valued, respected, cared about, and loved by others who are present in one's life [7]. This kind of support stimulates positive feeling and encourages employees' motivation[8].

In the university setting, social support is mostly related to the support given by co-worker and head of department. Behaviours such as assisting and helping others who are in needs in the form of mentoring, feedbacks or advices are examples of supporting behaviour which frequently practiced. According to [9], social support could be translated in the form of teamwork alike. Sharing of information and skills to solve the problem represent the higher-order of social support behaviour in the organisation. That is why, high social support typically coupled with higher employees' satisfaction. As stated by literature, social support is vital to one's job satisfaction. Since putting social support in place could enhance academicians' motivation and attitude at work [10], therefore this research focuses on identifying differences of social support and job satisfaction in between public and a private academicians. Also, to make comparison on the effect of social support on job satisfaction among academicians in a public and private universities.

Overall, this research investigates the role of social support and job satisfaction in education setting. Specific research objectives are as follow:

1. To identify the differences in terms of social support and job satisfaction levels among academicians in a Public and Private University in Malaysia.

2. To examine the differences in terms of social support and job satisfaction levels among academicians in a Public and Private University in Malaysia.

3. To compare the effect of social support on job satisfaction between academicians at Public and Private University in Malaysia.

\section{LITERATURE REVIEW}

\section{A. Social support in organization}

Social support plays an important role in organisation. It is defined as one's experience of being valued, respected, cared about, and loved by others [6, 7]. Researches have been suggested social support as vital factor that could promote effective workgroup interaction between employees, their supervisor, and co-workers in the organisation. Social support in workplace commonly categorised into two dimensions of supervisory support and co-worker support. Supervisor support concerns on a degree to which employees perceive their supervisors' support, encouragement, and concern [11]. Meanwhile, co-worker support refers to other employees' help, which usually given in the form of informal guidance while one's carrying out duties in the workplace[12].

An employee skill and attitude development at workplace are highly depending on degree to which supervisors appreciate, contribute and care about their well-being [11]. Support given by either supervisor or colleagues are perceived as a source emotion cultivation, wherein it worked as an instrumental resource at work [13]. Those who receive superior social support are generally scored higher in satisfaction level compared to those who receive lower support. As support protects and encourages individual to be more efficient, those who are high at it, usually displayed a greater degree of work motivation [8]. Likewise, social support enhances employees psychological wellbeing alike[14].

Furthermore, Malaysia is very different in terms of culture compared to Western countries. Malaysia culture has normally been seen as collectivist. Said country is rich in traditional values and put higher importance in harmonious relationship, respect for hierarchy, reciprocity and loyalty [13]. Western in other hand, view independency at top. Individual has a right to express their opinion regardless position. Within this context, individual interests and satisfaction have been placed as a priority. Dissimilar to Malaysia, due to high in collectivist tendency, most employees tend to view themselves as an organizational member instead of an unique individual. Those in this setting place higher priority in harmony, therefore altruism and good supervisory relationship are highlighted as among needs for employee satisfaction and well-being [15].

However, limited evidence has been available in discussing social support given in academic institutions. Due to different in work cultures, how social support is practiced could be dissimilar in both private and public setting.

H1: There is a significant difference in social support levels between academicians at public and private universities.

\section{B. Job satisfaction in organization}

Since the early research on employees, attitudes have been receiving a great deal of attention among researchers in attempt to measure employee behavior within the organization. Job satisfaction is often discussed as a result of one's interaction with the others and deals on his/her perception towards work environment [16]. It represents a set of external and internal factors that influence how employees feel about their work. mentioned job satisfaction as key factor to recognition, income, promotion, and achievement which ideally linked to feeling of fulfilment. It involves the experience of positive or negative feelings that underlines employees' behavior and attitude towards their work [18] .

There are three important features of job satisfaction [19] The first characteristic relates to the organisation's role. This notion believes that one should be guided by human values. Under this assumption, organisations will be expected to treat all of their workers fairly and with respect. In such a case, the assessment of job satisfaction may serve as a good indicator of employee effectiveness. Highly satisfied workers is a sign of good emotional and mental state of the employees, and a sign of good organisational culture has been putting into practice. Second, the behaviour of workers, depending on their level of job satisfaction 
. Thus, depending on employees' job satisfaction profile, the condition could be used to predict their future behaviour. Satisfied employee will result in positive behaviour and, whilst, dissatisfied employees will result in vice versa. Third, job satisfaction serves as an indicator of organisational activities. Through job satisfaction, evaluation of different levels of satisfaction in different organisational units can be defined, which in turn can serve as a good indication to enhance organisational performance $[17,18]$.

Theories on job satisfaction argues that satisfaction is related to the process of motivation. Herzberg's Theory of motivation states that the perception of job satisfaction is based on evaluation on the internal (motivator) and external (hygiene) factor. Maslow theory (1970), otherwise said that satisfaction requires a fulfilment of basic need based on the hierarchy of needs. Based on this theory, physiological need is needed before moving to the higher level needs of safety, belongingness, love, and lastly need of esteem.

However, little is known on the actual pattern of employee's job satisfaction in both public and private universities. Even though, many empirical have been offered in understanding how job satisfaction worked in the actual organisations, yet, limited point of view is available in explaining how it is functioned in educational institution. Addressing this gap, the first hypothesis is as below.

$\mathrm{H} 2$ : There is a significant difference in terms of job satisfaction levels between academicians at public and private universities.

\section{Social support and Job satisfaction}

High support from supervisors and co-workers could enhance academicians' motivation towards their work and improve positive attitude in an organisation. Previous researchers suggested that social support in the organisation may influence employee's positive feeling, work attitude and behavioral intentions [20]. Good supervisory and coworker support may bring the positive attitude to the job therefore contribute towards the increasing levels of employee's job satisfaction [21]. In 2017, research by also supported the previous research which are found that high support from supervisor and co-worker in organization give a positive effect on enhancing employee motivation and job satisfaction. This is because social support encourage positive relationship among employees, supervisor and coworker in organization which are can helps each other in doing job, solve problem which can enhance their satisfaction level.

In organisation, support not only related to help others in doing job, social support involved all aspect such as socioemotional and intrinsic support among employees in one team as a platform to enhancing job satisfaction and productivity. In addition, comprehensive model which is Job demand resources model (JD-R model) also explain the role of social support as a one of the factor that can enhance employee satisfaction in job. JD-R model recommended that working condition which are related to high demand of job and resources have a connection with individual performance in organisation [23] As for social support, the support form supervisor and co-worker in organisation was related to job resources aspect in JD-R model which act as positive aspect to enhance employees saticfaction.

Social Exchange Theory by Blau (1964) has supported the use of social support alike, wherein this construct has been used to modify the relationship between social support and job satisfaction. It has been found that the social construct helps buffering the effect of social interaction tendency towards job satisfaction. This is related to the mutual relationship between employees and organisation which is not only focuses on reward but also involves emotional and social aspects [12] [24]. As a result, progressing understanding between both parties enhances employees overall job satisfaction. In this study background, since Malaysia is a collectivist culture, the expectation for social support to be practiced in the current context is anticipated. As been emphasized in prior studies, social support in collectivist culture is higher due the norms and societal practice [15].

H3 : Social support significantly predicts job satisfaction of academicians in both public and private universities

\section{Conceptual model}

Figure 1 illustrates model of the current study. Social support acts as independent variable. Wherein, it represented by a total of two dimensions (i.e. supervisor support, coworker support). Whilst, job satisfaction is dependent variable.

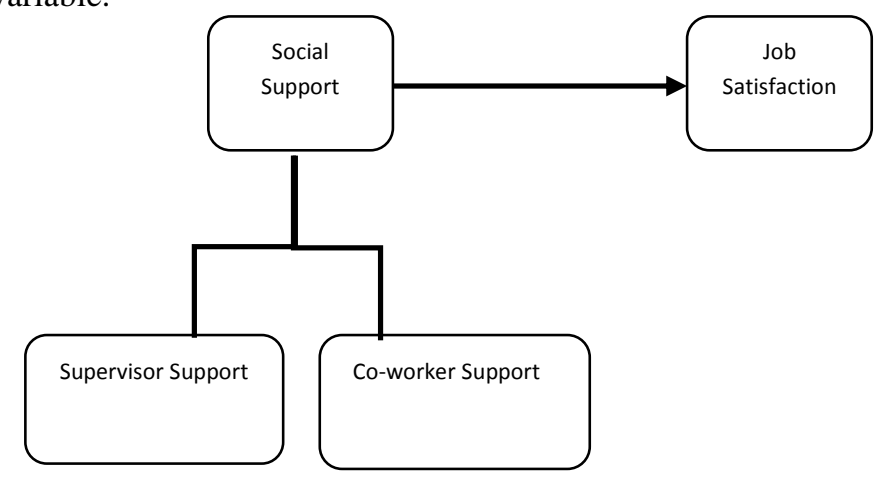

Figure 1: Conceptual Model

\section{METHODOLOGY/MATERIALS}

\section{A. Research Design, Population and Sample}

This research uses a quantitative approach with the utilize of self-administrated survey in collecting the data. This approach has several advantages. It is more suitable for research with large samples size and more objective. The data by quantitative approach is also considered more quantifiable and more appropriate to be generalize to a large population [25]. This research has been carried out in two type of higher education institutions in Malaysia which are public and private university as a population. A sample comprises of 210 academicians from public and 210 academicians from private universities, with an overall total of 420 when combined both. 
International Conference on Recents Advancements in Engineering and Technology (ICRAET-18) |15th and 16th March 2019|Siddhartha Institute of Technology \& Sciences, Telangana, India.

\section{B. Research Instrument}

The questionnaire of this study consisting of three major parts, which are demographic, social support scale and job satisfaction scale. This research was based on self-report questionnaire that focused on individual self-perception. Demographic data consisting personal details of the respondents of several questions about gender, ethnic group, religion, age, marital status, types of university, current position, levels of education and work tenure. Second part of questionnaires consist of eight items to measure social support which are divided four item for supervisor support and co-worker support. Last part in this questionnaire consist of eight items to measure respondent satisfaction toward their job.

Job satisfaction scale from Copenhagen Psychosocial Questionnaire (COPSOQ) was adopted to measure COPSOQ was developed by the Danish National Public in 1997 and the scale has good reliability [26]. The measurement by previous research reported high internal reliability with coefficient alpha value 0.89 [13]. The researcher also chose four-item scales developed by [27] to measure respondents' perceptions towards the level of social support from supervisor and co-worker they receive. Previous research [13] reported high internal reliabilities for both supervisor support $(\alpha=0.89)$ and co-worker support $(\alpha=0.91)$.

\section{Research Procedure and Data Analysis}

In this research, the first stage was researcher divided universities into two group or strata which are public and to represent a public university and Multimedia University was selected to represent a private university. In the second stage, researcher sought approval from Ministry of Education (MOE) to conduct a research among academician in University of Malaya (UM) and Multimedia University (MMU). After received approval from MOE, researcher continued with get the permission from Vice-Chancellor of UM and Vice-President (academic) of MMU to distribute questionnaires among their academicians. Researcher managed to get approval from MOE, UM and MMU and start distribute the questionnaires. Next, researcher distributed the questionnaires to the sample that was randomly selected from the population of academician in both UM and MMU. After obtaining the data from respondent, researcher continued with data analysis. The data was analyzed by using SPSS version 22 .

\section{RESEARCH FINDINGS}

The data was analyzed by using SPSS version 22 . Descriptive statistic was used to identify the mean value, frequency and percentage. In this research, mean level will represent the level of social support and job satisfaction and among respondent either low, moderate or high. Independent t-Test was performed to determine whether there is a significant difference in the mean of two independent samples [28]. Since this research examined the comparison of social support and job satisfaction between two sample groups, researcher selected independent-sample t-test as a method to analyze the data. Regression analysis respondent satisfaction. The job satisfaction sub-scale of private university. University of Malaya (UM) was selected

was performed to identify the effect of social support among respondent in this research.

\section{A. Demographic data of the respondent}

Table 1: Demographic data of the respondent

\begin{tabular}{llll}
\hline Variables & & Frequency & $\%$ \\
\hline Gender & Male & 195 & 46.4 \\
& Female & 225 & 53.6 \\
Types of & Public & 210 & 50.0 \\
University & University & & \\
& Private & 210 & 50.0 \\
& University & 27 & 6.4 \\
Position & Professor & 27 & 16.2 \\
& Assoc. Professor & 68 & 35.7 \\
& Senior Lecturer & 150 & 41.7 \\
& Lecturer & 175 & 59.8 \\
Education & PhD & 251 & 40.2 \\
& Master & 169 & 11.4 \\
Age & 25-30 years & 48 & 24.3 \\
& 31-34 years & 102 & 26.7 \\
& 35-39 years & 112 & 37.6 \\
\hline
\end{tabular}

Table 1 demonstrated that majority of the respondents in this research was female $(53.6 \%)$ and aged between 40 years old and above (37.6\%). The respondents were dominantly from the position of lecturers (52.6\%) and only 27 respondent $(6.4 \%)$ with the position as Professor. In terms of level of education, there are 251 respondent with $\mathrm{PhD}$ holder and 169 respondents with Master holder.

\section{B. $\quad$ Finding on objective 1}

Objective one in this research focused on compare and investigate the level of social support and job satisfaction among respondent in a public and a private university. Result in Table 2 presented the comparison level of social support and job satisfaction.

Table 2: Level of Social Support and Job satisfaction

\begin{tabular}{lccc}
\hline \multirow{2}{*}{$\begin{array}{l}\text { Types of } \\
\text { University }\end{array}$} & \multicolumn{2}{c}{ Social Support } & $\begin{array}{c}\text { Job } \\
\text { Satisfaction }\end{array}$ \\
\cline { 2 - 3 } & $\begin{array}{c}\text { Supervisor } \\
\text { Support }\end{array}$ & $\begin{array}{c}\text { Co-worker } \\
\text { Support }\end{array}$ & \\
\hline $\begin{array}{l}\text { Public } \\
\text { University }\end{array}$ & 3.61 & 3.68 & 3.86 \\
$\begin{array}{l}\text { Private } \\
\text { University }\end{array}$ & 3.68 & 3.74 & 3.76 \\
\hline
\end{tabular}

Table 2 represented the level of social support and job satisfaction among academicians in both university. High level of job satisfaction with the mean score 3.86 was represented by public university. Otherwise, the level of coworker support is high and supervisor support is moderate with the total mean score 3.68 and 3.61. Compared to private university, the finding revealed the high level of job satisfaction (mean value 3.76). Academician in a private university also have a high level of co-worker support and supervisor support with mean value 3.68 and 3.74

Overall, there are differences level of social support and job satisfaction between academicians in a public and a private university. There is a high level of job satisfaction 
among academician in a public and private university, but mean value indicated that academicians in public university higher than public university. In contrast, academicians private university have higher social support (supervisor support and co-worker support) compared to academicians in a public university that have moderate level of supervisor support.

\section{C. $\quad$ Finding on objective 2}

Based on objective two, researcher examined the differences of social support and job satisfaction between academicians at Public and Private University in Malaysia by using analysis of Independent t-Test. Result from t-Test analysis was concluded in Table 3 .

Table 3: t-Test Analysis

\begin{tabular}{lllllll}
\hline Element & $\begin{array}{l}\text { Type of } \\
\text { University }\end{array}$ & N & Mean & Df & T-test & Sig. \\
\hline $\begin{array}{l}\text { Supervisor } \\
\text { Support }\end{array}$ & Public & 210 & 3.61 & 418 & 0.843 & 0.399 \\
& Private & 210 & 3.68 & & & \\
$\begin{array}{l}\text { Co-worker } \\
\text { Support }\end{array}$ & Public & 210 & 3.68 & 418 & 0.934 & 0.351 \\
& Private & 210 & 3.74 & & & \\
$\begin{array}{l}\text { Job } \\
\text { satisfaction }\end{array}$ & Public & 210 & 3.86 & 418 & -1.948 & 0.05 \\
& Private & 210 & 3.76 & & & \\
\hline
\end{tabular}

*The mean difference is significant at values $p<0.05$

Result from t-Test analysis in this research demonstrated that there are no significant differences between academicians at public and private university in terms of their social support. Analysis reported that there is no significant differences of supervisor support $(\mathrm{t}(418)=0.843$, $\mathrm{p}>0.05)$ and co-worker support $(\mathrm{t}(418)=0.934, \mathrm{p}>0.05)$ between academicians in a public and private university. Based on the result, hypothesis one was rejected.

In terms of job satisfaction, researcher accept the hypothesis two because analysis t-Test reported the significant differences of job satisfaction between academician in a public university and private university $(\mathrm{t}$ $(418)=-0.948, \mathrm{p}<0.05$. Overall, academicians in a public and a private university only differ in terms of job satisfaction. Academicians in both university did not differ in terms of social support.

\section{D. $\quad$ Finding on objective 3}

In order to compare the effects of social support on job satisfaction among academicians in a public and private university, result from the regression analysis was presented in table 4.

Table 4. Effect of social support on job satisfaction

\begin{tabular}{llcll}
\hline $\begin{array}{l}\text { Types of } \\
\text { University }\end{array}$ & Variables & $\begin{array}{c}\text { Standardized } \\
\text { coefficients } \\
\text { Beta }(\beta)\end{array}$ & Sig, & \\
\hline $\begin{array}{l}\text { Public } \\
\text { University }\end{array}$ & $\begin{array}{l}\text { Supervisor } \\
\text { Support }\end{array}$ & 0.219 & 0.01 & 0.282 \\
& $\begin{array}{l}\text { Co-worker } \\
\text { Support }\end{array}$ & 0.351 & 0.000 & \\
$\begin{array}{l}\text { Private } \\
\text { University }\end{array}$ & $\begin{array}{l}\text { Supervisor } \\
\text { Support }\end{array}$ & 0.346 & 0.000 & 0.180 \\
& $\begin{array}{l}\text { Co-worker } \\
\text { Support }\end{array}$ & 0.108 & 0.192 & \\
\hline
\end{tabular}

Table 4 concluded the effect of social support on job satisfaction among academicians in public and private university. Result indicated that supervisor support $(\beta=$ $0.219, \mathrm{p}<0.05)$ and co-worker support $(\beta=0.351, \mathrm{p}<0.05)$ significantly affect job satisfaction among academicians in a public university. This result demonstrates higher supervisor and co-worker support related to high job satisfaction. Overall, social support in this research contributes about $28.2 \%$ to job satisfaction among academician in a public university.

In terms of private university, result found that supervisor support significantly affect job satisfaction $(\beta=0.346$, $\mathrm{p}<0.05)$. In contrast, co-worker support did not have significant effect on job satisfaction among academician in a private university $(\beta=0.108, p>0.05)$. Overall, $18.0 \%$ effect on job satisfaction was contributed by supervisor support. With this result, researcher accepted hypothesis 4 and confirmed that social support significant positively affect job satisfaction among academicians at public and private university in Malaysia.

\section{DISCUSSION}

This research concluded that social support and job satisfaction among academician in both public and a private university are considered high with mean value ranging from 3.68 to 3.76 , but still need an improvement by the university to achieve mean value 5.00. Based on result in this research, co-worker support among academicians in both university is consider high due to the nature of their job scope as a lecturer that require good cooperation at the first place. Part of academician duty is to engage in internal and external collaboration as means of sharing knowledges and improving university reputation. This behavior requires a certain degree of understanding, working, supporting and helping others to ensure a good outcome could be retrieved at the end period of the partnership This is seen in most universities nowadays, with special attention to public research university (i.e Research University), which this type of university put more weight on active contribution in grant and paper publication [29]

Described condition highlights a need for social interaction to accomplish research activities and publication. Working environment in public and private university also motivated by support from environment, enhancing quality of social relationship, friendly supervision and co-worker relationships assist to increase their effectiveness in work. Hence as mentioned by [30], positive social interaction with a supportive working environment may serve as a platform for individual to be more satisfied with their current job.

Interestingly, although it is previously mentioned that public universities engaged in more frequent collaborative initiatives, this research has revealed that supervisor support is however lesser in public universities, if compared to private universities. This finding is disproved some statements in the past, which public working environment is highly oriented to services, security and good relationship with others [31]. The diminishing supervisory support in the 
public university might be a sign that there is an ongoing crisis as employees in public are becoming more selforiented due to intense requirement. As mentioned by [32], the focus on R\&D within the university had contributed to sprouting of individualistic culture and low volunteerism behavior as academicians are inclined to engage in selfgoverning strategy to survive within this extreme environment.

Adding to this, the claim which private university is inclined towards individual achievement [5] is refuted in this study too. Current finding in this research, however revealed that supervisory support in the private university setting is higher compared to the public university. Higher supervisor support in a private university may be related to its business practice. As private university vision focuses more on achievement and profit orientation [5], supervisor role has been greatly utilized in coaching and giving a specific direction to the existing employees and a new joiner. In other perspective, certain private university bounds to lower job security. This might indirectly encourage academician in those setting to put on more effort, and seek more supervisor support in challenging situation.

In terms of job satisfaction, even though the mean value indicated both universities had high level of job satisfaction, there are significant differences found between both samples. Consistent with a research by [33], this study likewise found that the degree of job satisfaction is different in both setting. Result indicated that academicians in public university are displaying higher job satisfaction compares to private university. A plausible reason could be justified by the levels of job security. Private university has been associated to lower security in comparison to public university. In most cases, employees in public university displayed higher satisfaction due to security in salary and benefits schemes [34].

In addition, there are significant effect of social support on job satisfaction among academicians in Malaysia public and private university. As aforementioned, the level of social support and job satisfaction are high, but the result demonstrated only $28.2 \%$ social support contributed to enhance job satisfaction among academicians in public university. Result also indicated that only $18 \%$ social support contributed to enhancing job satisfaction among respondent in this study. This result concluded the differences effect of social support on job satisfaction between academicians in a public and a private university.

Overall, below than $30 \%$ contribution of social support to enhance job satisfaction. Another $70 \%$ may related to others variable that has not been studied. Furthermore, since Malaysian practices a supportive environment and helping behaviour, thus why it does not appear to deliver such a huge effect on employees' job satisfaction. As mentioned by [35], non-financial reward such as recognition, praise and appreciation employee job can help them feel comfortable and satisfy in doing their job. Review on factors affected job satisfaction among academician by [36] also stressed out that personal ambition, recognition and reward become a significant factors that contributed to job satisfaction among academician now days.

\section{IMPLICATION OF THE RESEARCH}

The current research highlights an empirical investigation in comparing the effect of social support on job satisfaction among academicians in Malaysia public and private university. Based on the findings, this research highlights several important contribution and suggestions to both theoretical and legislation. In terms of theoretical implication, this research contributes to the current body of knowledge in several techniques. In the pursuit of understanding human interaction and attitude behaviour, it is essential to indicate and understand the link between social support and job satisfaction among employees in an organisation. This research contributes to relevant literature by investigating the link and the effect between social support and job satisfaction especially in the academic setting.

This research also addresses several practical implications for organisation. Firstly, this research provides information on the importance of enhancing job satisfaction among academicians in Malaysia by focused on the implementation of the social support. Academicians with high social support always willing to help others that exceed their job scope and will concurrently help others seek ways to enhance university's performance. The research findings also help management of public and private to design a good intervention or training to enhance job satisfaction by focusing on promoting social support among academician. Based on the research findings, university and higher education in Malaysia need to emphasis more on promoting social support.

\section{CONCLUSION}

Based on this research outcome, social support become an important aspect to improving job satisfaction among Malaysian academicians. In Malaysia's public and private universities, support from supervisor/head of department and co-worker respond as positive element to enhance academician's satisfaction. Since there are significant differences of social support among academicians at public and private sectors, universities need to identify the most needed element to help their academicians to enhance their job satisfaction and promote social support. Even though the level of job satisfaction among both academicians are considered at high level, the mean values only around 3.7 to 4.00. There is need to promoting social support to enhance job satisfaction in highest level by understanding in the differences need and desire by academicians in both public and private university.

This research also reported the contribution of social support on job satisfaction that less than $30 \%$ for both university. Future research needs to explore more variable that can give huge impact on job satisfaction among academicians in a public and private university. At the same time, promoting the social support in higher education also important to help academicians survive in the era of IR4.0 that gives huge impact on their career life. Since this study was carried out in Malaysia, it spreads the information and 
studies regarding the comparison of social support and job satisfaction between academicians in public and private university. Since Malaysia was highly influenced by collectivism culture, this research also explains the crucial role of social support among academicians to enhancing job satisfaction. The role of university that stresses more on social support could help to enhance social interaction tendency and job satisfaction among academicians.

\section{REFERENCES}

1. Idris, R., Industrial Revolution 4.0: An Overview of Readiness and Potential Economic Effects in Malaysia from Millennial's Perspective. World Scientific News, 2019. 118: 273-280.

2. Shahroom, A.A., \& Hussin, N., Industrial Revolution 4.0 and Education. International Journal of Academic Research in Business and Social Sciences, 2018. 8(9): p. 314-319.

3. Ahmad, W.A., \& Abdurahman, S. M., Job Satisfaction among Academic Staff of Universiti Utara Malaysia: A Work Environment Perspective Mediterranean Journal of Social Sciences 2015. 6(32): p. 251-256.

4. Arma Noor , N.H.I., Occupational Stress and Its Associated Factor among Academician in a Research University, Malaysia. Malaysian Journal of Public Health Medicine, 2016. 16(1): p. 81-91.

5. Price, C., \& Beaver, G., The Rise and Rise of the CU: The Emerging Corporate Learning Agenda. The International Journal of Management Education, 2001. 1(3): p. 17-26.

6. Kasraie, S., Parsa, S., Hassanim, M. \& Ghasem-Zadeh, A, The Relationship between Quality of Work Life, Job Stress, Job Satisfaction and Citizenship Behavior in Oshnaviyeh Hospital's Staff. Patient Safety \& Quality Improvement, 2014. 2(2): p. 78-81.

7. Md Aris Safree, M.Y., \& Mariam Adawiah, D. , The Relationship between Social Support and Psychological Problems among Students. International Journal of Business and Social Science, 2012. 1(3): p. 110-116.

8. Krishnan, J., \& Mary, S. V. , Perceived Organizational Support- An Overview On Its Antecedents and Consequences. International Journal of Multidisciplinary Research, 2012. 2(4): p. 1-13.

9. Brough, P., \& Frame, R. , Predicting Police Job Satisfaction, Work Well-Being And Turnover Intentions: The Role of Social Support and Police Organisational Variables. Journal of Psychology, 2004. 33(8): p. 8-18.

10. Costa-Lobo, C., P. Silva, Ribeiro, A., and S. Silva. The impact of social support on academic motivation levels in higher education. in Proceedings of INTED2017 Conference2017. Valencia, Spain.

11. Eisenberger, R., Stinglhamber, F., Vandenberghe, C., Sucharski, I. L., \& Rhoades, L., Perceived Supervisor Support: Contributions to Perceived Organizational Support and Employee Retention. Journal of Applied Psychology, 2002. 87(3): p. 565-573.

12. Cromwell, S.E., \& Kolb, J. A., An Examination of WorkEnvironment Support Factors Affecting Transfer of Supervisory Skills Training to the Workplace. Human resource Development Quarterly, 2004. 15(4): p. 449472.

13. Siti Aisyah, P., Impact of Work Design on Psychological Work Reactions and Job Performance among Technical Workers: A Longitudinal Study in Malaysia. 2010, University of Waikato: Hamilton.

14. Soulsby, L. and K. Bennett, Marriage and Psychological Wellbeing: The Role of Social Support. Psychology, 2015. 6: p. 1349-1359.
15. Robinson, C.H., \& Betz, N. E. , A Psychometric Evaluation of Super's Work Values Inventory-Revised. Journal of Career Assesment, 2008. 16(4): p. 456-473.

16. Locke, E.A., The Nature And Causes Of Job Satisfaction. . Handbook of industrial and organizational psychology 1976, In M.D. Dunnette (Ed). Chicago: Rand McNally. 1297-1349.

17. Aziri, B., Job Satisfaction: A Literature Review. Management Research and Practice, 2011. 3(4): p. 77-86.

18. Davis, K.N., J.W. , Human Behavior at Work: Organisational Behavior. Vol. 7 edition. 1985, McGraw Hill, New York.

19. Spector, P.E., Job Satisfaction: Application, Assessment, Causes and Consequences. 1997, Thousand Oaks, CA,: Sage Publications, Inc.

20. Cropanzano, R. and M.S. Mitchell, Social Exchange Theory: An Interdisciplinary Review. Journal of Management, 2005. 13(6): p. 874-900.

21. Khalid, S., M.Z. Irshad, and B. Mahmood, Job Satisfaction among Academic Staff: A Comparative Analysis between Public and Private Sector Universities of Punjab, Pakistan. International Journal of Business and Management 2012. 7(1): p. 126-136.

22. Orgambídez-Ramos, A.A., H., Work engagement, social support, and job satisfaction in Portuguese nursing staff: A winning combination. Applied Nursing Research 2017. 36: p. 37-41.

23. Kim, S.H., \& Wang, J.S., The Role of Job DemandsResources (JDR) between Service Workers' Emotional Labor and Burnout: New Directions for Labor Policy at Local Government. International Journal of Environmental Research and Public Health, 2018(15): p. 1-31.

24. Tek-Yew, L., The Relationships between Perceived Organizational Support, Felt Obligation, Affective Organizational Commitment and Turnover Intention of Academics working with Private Higher Educational Institutions in Malaysia. European Journal of Social Sciences, 2009. 9(1): p. 72- 87.

25. Choy, L.T., The Strengths and Weaknesses of Research Methodology: Comparison and Complimentary between Qualitative and Quantitative Approaches. IOSR Journal Of Humanities And Social Science 2014. 19(4): p. 99104

26. Kristensen, T.S., et al., The Copenhegen Psychosocial Questionnaire : A tool fro the assessment and improvement of the psychosocial work environment Scand J Work Environ Health, 2005. 31(6): p. 438-449.

27. O'Driscoll, M.P., \& Dewe, P. J. , Mediators and Moderators of Stressorstrain Linkages Research In Occupational Stress And Well-Being 2001. 1: p. 257 287.

28. Kim, T.K., T Test as a Parametric Statistic. Korean Journal of Anesthesiology, 2015. 68(6): p. 540-546.

29. Mohrman, K., Ma, W., \& Baker, D. , The Research University in Transition: The Emerging Global Model. Higher Education Policy, 2008. 21: p. 5-27.

30. Heaphy, E. and J.E. Dutton, positive social interactions and the human body at work: linking organizations and physiology. Academy of Management Review2008. 33(1): p. 137-162.

31. Wright, B., E., \& Davis, B., S., Job Satisfaction In The Public Sector: The Role of the Work Environment. The American Review of Public Administration, 2003. 33(70): p. 70-90.

32. Ujang., Z., Menjana Minda Kreatif dan Inovatif Perutusan Tahun Baru Naib Canselor 2011. 2011, 
Skudai: : Penerbit UTM Press.

33. Fang-Mei, T., Job Satisfaction of University Staff. The Journal of Human Resource and Adult Learning, 2014. 10(1): p. 51-64.

34. Sonmezer, M.G., \& Eryaman, M. Y. , A Comparative Analysis of Job Satisfaction Levels of Public And Private School Teachers. Journal of Theory and Practice in Education, 2008. 4(2): p. 189-212.

35. Imran, A., Ahmad, S., Nisar, Q. A., \& Ahmad, U. , Exploring Relationship among Rewards, Recognition and Employees' Job Satisfaction: A Descriptive Study on Libraries in Pakistan Middle-East. Journal of Scientific Research, 2014. 21(9): p. 1533-1540.

36. Basak, S.K., Theoretical Framework Of The Factors Affecting University Academics' Job Satisfaction International Business \& Economics Research Journal, 2015. 14(2): p. 317-326. 